\title{
Wake-Up Calls
}

Dr. G. Subramanyam

Director, Prof. \& Head of the Dept. of Cardiology, College of Medical Sciences, Bharatpur, Chitwan (Dist.), Nepal

Worldwide data suggest that people are living longer than previously in developed countries. Reports predict that if the present trend of increase in the life expectancy continues through this century, most babies born after 2000 will be able to celebrate their $100^{\text {th }}$ birthday. However, researchers also have noticed an increased trend of the prevalence of obesity in wealthy countries and assume that it might slow down the trend of rising life expectancy. Similarly increased life expectancy means increased prevalence of coronary artery diseases and this may also put some brakes in this trend. However, there is a greater advancement and achievement in the early recognition and treatment of coronary artery diseases especially in developed nations; it indicates that there is no stop in rising life expectancy.

On the other hand, this scenario is markedly different in developing countries. The developing nations are just getting rid of infectious and communicable diseases as a result of some improvement in sanitation and living conditions, and also because of the easy availability of effective antibiotics and antimicrobial treatment. But there is also a rising trend in non-infectious conditions such as cardiovascular diseases and oncological conditions. This is not only because of some rise in life expectancy but also due to sedentary life style and diet containing high fat and carbohydrates. So, it seems the long life is still a distant privilege for the future generations in these countries until there is satisfactory development in the management of the major contributors of mortality and morbidity; cardiovascular, cerebrovascular and oncological diseases.

Nepal, being one of the representatives of latter group, is experiencing similar trend. So, the future generations of the Nepal and other developing world will not be lucky enough to enjoy the privilege of long life. Therefore, apart from strengthening the efforts against infectious diseases, there is a strong need in the advancement of facilities dealing with major determinants of mortality and morbidity in future scenario, such as coronary artery diseases and other cardiovascular conditions, cerebrovascular diseases, and oncological conditions. In addition, 
there is also a strong need for authentic researches on health related matters of the communities. So, it is high time to start higher education in super specialty such as cardiology, neurology and nephrology, and other areas of medicine. These courses, apart from emphasizing on clinical skills and community services as the main objectives, should produce high level researchers capable of carrying independent researches. In this regard, the steps taken by Kathmandu University in starting DM and MCh courses on various subjects at the College of Medical Sciences Teaching Hospital, Bharatpur are timely and appreciable.

Kathmandu University has always been a pioneering institution in starting various innovative and practical courses in the country and such milestones will also be a leap in medical education. We fully agree with the idea that Nepal needs to put brakes on the conventional development and should make leaps not only in economic but also in every aspect of development. The steps taken by Kathmandu University should be encouraged and supported by the medical community. We are sure these measures taken by the University and the efforts taken by the persons behind these programs will be remembered forever not only by the medical community of the nation but also by the general public.

As these courses are research based advance clinical degrees, priorities are on both advance research and clinical super specialty subjects. Therefore, we hope these programs will produce not only highly skilled, community and service oriented specialists but also well trained researchers and strengthen the research wing of the medical science. We hope these efforts and steps will also make a wake up calls to various institutions in collaborating for the success of this historymaking effort of Kathmandu University. 